\title{
JUDITH BUTLER E A CONSTRUÇÃO SOCIAL DO SUJEITO DE DIREITO NA APARÊNCIA DO GÊNERO
}

André Luiz Alves da Silva ${ }^{93}$

\begin{abstract}
RESUMO
Este artigo buscar analisar a constituição do sujeito de direito a partir da obra de Judith Butler. Nas questões de gênero, temos diferentes pressupostos: uns pela metafísica da substância, já pelo método de Butler a desconstrução de ideias pré-discursivas. Mostrando o vínculo de seu pensamento a partir da genealogia do gênero com o de Michel Foucault, tentaremos mostrar o caráter ficcional do sujeito de direito. Examinamos brevemente os estudos de Butler sobre o sujeito, o desejo e o reconhecimento, desde seus primeiros trabalhos sobre Hegel. Analisando gênero da forma como Butler propõe, buscamos elucidar seu caráter de performatividade.
\end{abstract}

Palavras-chave: sujeito, direito, gênero.

\begin{abstract}
This article seeks to analyze the constitution of the subject of law from the work of Judith Butler. In gender issues, we have different assumptions: some by metaphysics of substance, but by Butler's method the deconstruction of pre-discursive ideas. Showing the link of his thought from the genealogy of the genre with that of Michel Foucault, we will try to show the fictional character of the subject of law. We briefly examine Butler's studies of subject, desire, and recognition since his earliest works on Hegel. Analyzing gender in the way that Butler proposes, we seek to elucidate his performativity character.
\end{abstract}

Keywords: subject, law, gender.

\section{O SUJEITO DE DIREITO SOB O RISCO DA PERDA DE DIREITOS}

As manifestações de tentativas de proibição de realização de recentes eventos acadêmicos e de arte parecem de fato sugerir que estamos em uma época difícil para as ciências humanas, para a cultura, para a arte e para tudo o que faz crítica ao establishment político conservador e da atual sociedade brasileira. ${ }^{94}$ Não obstante os ataques às exposições e espetáculos de arte, uma filósofa importante da academia foi hostilizada em sua visita ao Brasil. Além da manifestação em frente ao SESC Pompéia, em um evento sobre a democracia, do qual foi curadora, sob um protesto que se referiu a ela como uma

\footnotetext{
93 Pós-graduação em Filosofia e Pensamento Político Contemporâneo pelo Centro Universitário Assunção - UNIFAI (concluída em 2017) e pós-graduação Filosofia e Humanidades pelo Centro Universitário Ítalo Brasileiro - Uniítalo (concluída em 2012), cursei Pós-Graduação em Filosofia e Teoria do Direito pela Pontíficia Universidade Católicas de Minas Gerais PUCMinas (2016 - conclusão somente das disciplinas), bacharel em Ciências Contábeis pelo Centro Universitário Estácio Radial (concluída em 2003) e licenciado em Filosofia pelo Centro Universitário Assunção - UNIFAI (concluído em 2015). ${ }^{94}$ A revista CULT no 230 de dezembro de 2017 trouxe um dossiê sob o título de "Arte sob Coerção: Moralismo privado no espaço público", onde relata e análise uma série de movimentos dessa natureza durante de julho à novembro de 2017, como por exemplo, o cancelamento da exposição Queermuseu pelo Santander Cultural "depois de uma onda de protestos no local e nas redes sociais organizadas pelo MBL e por grupos religiosos” (p.14).
} 
"assassina de crianças", "pedófila" "aberração", a filósofa Judith Butler foi hostilizada junto de sua companheira em um aeroporto de São Paulo, quando embarcava em retorno ao seu país ${ }^{95}$, por pessoas que, se leram algo de seus densos textos filosóficos, talvez não tenham efetivamente compreendido, tendo em vista uma reação tão violenta contra a filósofa ${ }^{96}$. Influenciadas por uma narrativa chamada "Ideologia de gênero" ${ }^{97}$, essas pessoas atacam intelectuais, artistas e suas obras por acreditarem na sacralidade do binarismo de gênero.

O que parece pressupor tal narrativa e tais manifestações, é que se Deus ou a biologia determinou formas masculinas ou femininas, ninguém tem o direito de ser ou de fazer diferente desta determinação, e se o fizer, em resumo não está apta a ter direitos, quiça o direito à própria vida. O que mascara toda esta discussão em torno de quem levanta a bandeira contra àquilo que denominam como "ideologia de gênero", é que, o que chamamos de masculino ou feminino, que para autores como Judith Butler e Michel Foucault, são conceitos ou verdades que construímos e generalizamos em torno de coisas singulares que, sendo obervadas mais atentamente, se manifestam multifacetadas e plurais e não necessariamente têm origem direta nos órgãos sexuais, em uma mera relação de causalidade. Tais singularidades, se analisadas em suas próprias experiências e contextos, como toda singularidade deveria ser analisada, segundo aprendemos desses dois filósofos, mostra que o que existe é uma grande variedade de modos de existir dos sujeitos enquanto "homem", "mulher" ou qualquer outra denominação que se queira dar. O que se pode extrair através de uma genealogia do poder, em torno da narrativa da "ideologia de gênero", é que ideologia quem tem mesmo, é quem, por causa de privilégios de poder, argumenta apenas pela predeterminação natural do binarismo de gênero, justificando seja por determinismo biológico ou decreto divino, relações de hierarquia e opressão de pessoas em função do seu gênero. O termo "ideologia de gênero", utilizado pelos antagonistas de Butler e por todos aqueles que tem sido contra os estudos de gênero e a militância queer e LGBT, foi popularizado por um acadêmico católico argentino chamado Jorge Scala, que de alguma forma, faz ressonância àquilo que o teólogo cardeal Joseph Ratzinger escreveu em

\footnotetext{
95 O fato foi noticiado por vários jornais do país e na plataforma do Youtube é possível assistir o vídeo gravado por um dos próprios manifestantes contra a presença de Butler no Brasil. Veja, por exemplo, no link: http://www.diariodepernambuco.com.br/app/noticia/viver/2017/11/10/internas viver, $730360 /$ filosofa-judith-butler-eperseguida-e-hostilizada-por-grupo-ao-sair-do.shtml. Acessado em 15/01/2018.

${ }_{96}$ Conhecer o perfil destes manifestantes é algo que deve ser levado em consideração. A Fundação Escola de Política e Sociologia de São Paulo - FESPSP - realizou por meio de membros de seu corpo docente e discente sob orientação da Doutora em Antropologia Isabela Oliveira Pereira da Silva, uma pesquisa sob o título de “'Ideologia de Gênero' x 'Ideologia de Gênesis': Percepções e controvérsias nas manifestações pró e contra"' sobre os manifestantes contrários e a favor da presença de Judith Butler por ocasião do no Seminário Internacional “Os fins da democracia”, realizado pelo Sesc Pompeia, na manhã de 07 de novembro de 2017, sob a curadoria da filósofa. Tal pesquisa foi divulgada pela revista Exame na reportagem de Luisa Calegari "O que pensam os manifestantes contra e a favor de Judith Butler" no link https://exame.abril.com.br/brasil/o-que-pensam-os-manifestantes-contra-e-a-favor-de-judith-butler/ (Acessado em 10/03/2018) e também pode ser encontrada em um ensaio da antropóloga Dra. Isabela Oliveira no site Nexo sob o título "Gênero, política e religião nos protestos contra Judith Butler" no link: https://www.nexojornal.com.br/ensaio/2017/G\%C3\%AAnero-pol\%C3\%ADtica-e-religi \%C3\%A3o-nos-protestos-contraJudith-Butler (Acessado em 10/03/2018) Os resultados dessa pesquisa podem ser encontrados no link http://www.neu.city/ (Acessado em 10/03/2018).

${ }_{97} \mathrm{O}$ termo teria sido popularizado entre os católicos por Jorge Scala, um acadêmico argentino, cujo livro tem como título "Ideologia de Gênero: Neototalitarismo e a morte da família", publicado pela Editora Katechesis no Brasil.
} 
um texto em 2004. Do qual comenta a pesquisadora Luisa Helena Torrano (2010, p. 60) em sua dissertação:

Em um texto de 2004, portanto um ano antes de ser nomeado Papa Bento XVI, Joseph Ratzinger manifesta seu apoio a esse feminismo que sustenta uma relação de oposição entre homens e mulheres, e adverte contra os perigos de novas políticas de gênero que tomam o gênero como uma função social instável (FW 118), explicando-o como uma tentativa humana de se livrar de suas determinações biológicas, transcender as leis naturais e culturais: o pecado da soberba. A preocupação de Ratzinger é com teorias nas quais "diferença física, nomeada sexo, é minimizada, enquanto o elemento puramente cultural, nomeado gênero, é enfatizado ao máximo e tido por primário" (Ratzinger, "Carta aos bispos da Igreja Católica em Colaboração com Homens e Mulheres na Igreja e no Mundo", apud FW).

Observamos nestas abordagens uma certa confusão. Judith Butler estaria afirmando não haver sexos biológicos distintos? Será que estas novas feministas, entre as quais, Judith Butler, desejam destruir os gêneros? Estaria ela dizendo que não existe "mulher" ou "homem" e que as pessoas podem livremente escolher seu gênero a hora que bem entenderem? Confusão maior não poderia ser diferente. E não é isso o que dizem seus textos, por sinal bastante densos. Analisando atentamente ao trabalho que Butler desenvolve, percebe-se que vai muito além de uma simples questão de escolha do gênero. O que pode até surpreender alguns, que não a leram atentamente e que se contentam em tirar do contexto fragmentos de sua obra, é que Butler evidenciará exatamente o contrário disto. Mostrando como o gênero é como uma grade na qual somos compelidos a nos moldar, por causa de uma série de normatividades, Butler evidencia que o gênero nada mais é do que o efeito de dispositivos. Cujo sentido foucaultiano de dispositivo, sintetiza CASTRO (2016, p. 124)

O dispositivo é a rede de relações que podem ser estabelecidas entre elementos heterogêneos: discursos, instituições, arquitetura, regramentos, leis, medidas administrativas, enunciados científicos, proposições filosóficas, morais, filantrópicas, o dito e o não dito.

Tais dispositivos nos assujeitam à uma performatividade de um gênero sob determinadas formas. Neste sentido, a questão da escolha é até bem restrita. E não que não existam escolhas. Mas é aí mesmo no processo de assujeittissement (subjetivação) que nos constituímos enquanto sujeitos numa verdadeira relação paradoxal de formação e regulação simultâneas do sujeito (BUTLER, 2017, p. 40)

Neste estudo pretendemos destacar alguns pressupostos das teorias butlerianas em torno da questão do sujeito de direito. Tentaremos mostrar que Butler está numa certa perspectiva do construcionismo social, embora ela mesma destaca os limites dessa perspectiva, como veremos. Também o pressuposto de Butler em rechaçar a metafísica da substância, ao lado de autores como Nietzsche e Foucault. Seu pensamento também dialoga criticamente até certo ponto com fenomenólogos e existencialistas (Butler foi orientada por um fenômenologo em seu doutorado). Assim, entendemos que 
a autora faz uma genealogia do sujeito enquanto construção social. Para isto, a autora lança mão das ferramentas e alguns dos métodos do filósofo francês Michel Foucault. Pode-se dizer que Butler é uma continuadora do trabalho do filósofo francês, posto que as várias questões abordadas por Foucault como práticas discursivas, regimes de verdade, governamentalidade, dispositivos, poder, subjetivação, genealogia, etc. estão muito presentes em seu trabalho sobre a constituição do sujeito. Porém, deve-se deixar claro, que Butler não é integralmente foucaultiana, há que se reconhecer divergências precisas entre os trabalhos de ambos, embora o número de convergências seja bem considerável. ${ }^{98}$

Finalmente também iremos brevemente apontar as preocupações butlerianas com o sujeito que se iniciaram desde de seus primeiros estudos e que como a própria autora segue com estas questões em suas produções e abordagens em suas mais diversas obras e trabalhos acadêmicos.

Reconhecemos que trata-se de um estudo muito amplo com várias possibilidades de abordagens. Nosso estudo, pretende uma visão geral como aproximação inicial para uma leitura foucaultiana da teoria butleriana. Esperamos com este texto, mostrar a importância do trabalho de Judith Butler na esteira daquilo que foi de alguma forma iniciado por Michel Foucault, isto do ponto de vista de meu interesse acadêmico, já que me propus em minha pesquisa para produção da disseração de mestrado a interlocução entre o pensamento de ambos. Que possibilidades a filosofia de Judith Butler traz para pensarmos o sujeito de direito? Ao meu ver, um trabalho como este se faz absolutamente necessário quando direitos estão sendo desmontados ao mesmo tempo em que se faz campanha a um conservadorismo excludente de certos grupos.

\section{JUDITH BUTLER E DES(CONSTRUÇÃO) CULTURAL DO SUJEITO DE DIREITO}

Alguns autores tem localizado Judith Butler na teoria do construcionismo cultural. Tal abordagem serve para entendermos os pressupostos a partir dos quais ela faz as suas afirmações e conduz seus estudos acerca do sujeito de direito. O construcionismo cultural ou social é uma teoria crítica das ciências humanas que abandona o idealismo e a metafísica da substância, para uma abordagem dos fenômenos culturais como sendo eminentemente construído pelos próprios seres humanos em suas relações sociais.

Pesquisadores brasileiros tem categorizado também o pensamento de Michel Foucault no construcionismo social, a título exemplar citamos a historiadora e doutora em educação Guacira Lopes Louro (p.31, 2000) que infere a abordagem de Michel Foucault na perspectiva do construcionismo social.

No estudo da história e da sociologia da sexualidade, Foucault pode ser considerado um dos mais influentes teóricos da abordagem do "construcionismo social". O próprio trabalho de Foucault pode ser mais bem compreendido, entretanto, se observamos que ele dava continuidade a uma tradição de crítica ao essencialismo sexual que tinha uma série de diferentes fontes.

\footnotetext{
${ }^{98}$ Um exemplo de divergencia entre Butler e Foucault é a abordagem psicanalítica nos processos de subjetivação em seu texto A vida psíquica do Poder: Teorias da Sujeição, algo sempre evitado pelo filósofo francês.
} 
Se considerarmos a genealogia foucaultiana, vemos que tanto o seu empreendimento genealógico com relação a "sexualidade" no qual ele evidenciou a construção do termo enquanto algo que surgiu apenas a partir do século XIX (FOUCAULT, p. 7, 2014) no contexto das ciências médicas, quanto o empreendimento genealógico de Judith Butler em Problemas de Gênero que evidencia que as "categorias de gênero surgem em campos discursivos muito distintos" os quais são dados a partir de "regimes de poder/discurso" (BUTLER, 2015, p.10), veremos que ambos de fato abordam as questões sobre sexo e gênero a partir da perspectiva de construção social. Assim em ambos os filósofos, o binômio saber-poder em que encontram imbricadas as ciências como dispositivos de poder, e a história que se conta comumente acerca de sexo e gênero, evidenciam que são efeitos de práticas de linguagem construídos socialmente e contextualmente, os quais não refletem universalmente todas as singularidades acerca dos sujeitos a que se referem. Ou seja, as ideias que temos sobre sexo e gênero, tratar-se-iam sempre de construções sociais sem correspondência direta e definitiva às próprias coisas.

Ao problematizar a luta pela identidade da mulher nos movimentos feministas, como muitas vezes tratado de forma homogeneizada, Butler mostra que o sujeito de direito, como criação do aparato jurídico, se aferra sobre uma certa destinação biológica. Por isso, é preciso mostrar que a própria distinção entre sexo e gênero, nega tal determinismo. A questão não é mais abordar o gênero como cultura e o sexo como biológico. O que Butler procura é problematizar é tanto o gênero como o sexo dito feminino enquanto construções culturais. Como uma "crítica às categorias de identidade que as estruturas jurídicas contemporâneas engendram, naturalizam e imobilizam” (BUTLER, 2015, p. 24). Para Butler

a distinção entre sexo e gênero atende a tese de que, por mais que o sexo pareça intratável, em termos biológicos, o gênero é socialmente construído: consequentemente, não é nem o resultado causal do sexo nem tampouco tão aparentemente fixo quanto o sexo. (p. 26)

Portanto não há causalidade entre sexo e gênero. E a sua fixidez só existe ficcionalmente porque o aparato jurídico interpretou a biologia dessa forma. Fica clara a inversão que Butler analisa, posto que ao invés de um gênero sexual ou determinado pelo sexo biológico, o que se tem é um sexo "generificado". Ou seja, se o gênero é construído culturalmente e o sexo é interpretado a moda do gênero, o sexo da forma como definem a biologia e o aparato jurídico são criações ou construções culturais. Deixemos que a própria Butler fale:

Se o gênero são os significados culturais assumidos pelo corpo sexuado, não se pode dizer que ele decorra de um sexo desta ou daquela maneira. Levada a seu limite lógico, a distinção sexo/gênero sugere uma descontinuidade radical entre corpos sexuados e gêneros culturalmente construídos. (p.26) 
Porém, devemos ter um certo cuidado em estigmatizar tanto Butler quanto Foucault como construcionistas sociais ipsis litteris. Especificamente sobre Butler, em uma entrevista organizada pelas pesquisadoras holandesas Baukje Prins da Universidade de Amsterdã e Irene Costeira Meijer da Universidade de Maastricht sob o título "Como os corpos se tornam matéria: entrevista com Judith Butler", ao ser perguntada sobre a inserção de sua filosofia a um desconstrutivismo, especialmente em seu texto Bodies that matter (1993) ela responde:

Gosto muito deste último resumo de minhas reivindicações. Entretanto, acho que pode ser um erro argumentar que Bodies That Matteré um trabalho construtivista ou que procura considerar a materialidade em termos construtivistas. Seria igualmente correto - ou possível - dizer que ele busca entender por que o debate essencialismo/construtivismo tropeça em um paradoxo que não é facilmente ou, na verdade, não é jamais superado. Assim como nenhuma materialidade anterior está acessível a não ser através do discurso, também o discurso não consegue captar aquela materialidade anterior; argumentar que o corpo é um referente evasivo não equivale a dizer que ele é apenas e sempre construído. De certa forma, significa exatamente argumentar que há um limite à construtividade, um lugar, por assim dizer, onde a construção necessariamente encontra esse limite. (PRINS e MEIJER, 2002)

O que deve ficar claro, é que para os dois filósofos, Butler e Foucault, não é que planejam eliminar as distinções do sexo ou do gênero, mas sim que as categorizações que se fazem em torno são sempre provisórios, temporais e mobilizados por disputas de poder e não correspondem a um espelhamento fiel entre natureza e realidade humana. Quando Michel Foucault deu uma conferência na PUC-Rio em 1973 acerca da Verdade e as formas jurídicas, em sua primeira palestra, em sua leitura própria de Nietzsche ressaltou este sentido construto do conhecimento, fez afirmações como "o conhecimento é uma invenção e não tem origem”, "não está ligado a natureza humana”, "o conhecimento não tem relações de afinidade com o mundo a conhecer" e "não é natural à natureza ser conhecida." (FOUCAULT, 2013, p. 26-27), mostrando seu vínculo com a genealogia nietzschiana em sua ruptura com a filosofia ocidental da metafísica da substância. A genealogia escancara a relação promíscua, violenta e sempre intrínseca que existe no binômio saber-poder "Se não existe mais relação entre o conhecimento e as coisas ao conhecer, se a relação entre o conhecimento e as coisas conhecidas é arbitrária, de poder e de violência [...]” (p.28). Assim, o conhecimento se revela como "relações de luta e de poder" (p. 31).

A teoria do sujeito de Butler tem a mesma perspectiva genealógica de Foucault. O tema de Problemas de Gênero, o livro mais famoso de Butler lançado em 1990, é uma genealogia do gênero a partir da ideia de poder que tem como efeitos as categorias de sexo, gênero e desejo. (2015, p.9). Não se trata da origem dessas categorias, mas de um entorno de apostas políticas efetuadas por práticas e discursos onde as categorias de identidade são os seus efeitos. Há aqui, sem dúvida, uma forte aproximação de Butler com a ideia de Michel Foucault sobre genealogia e poder.

E o que afinal é o "sexo"? É ele natural, anatômico, cromossômico ou hormonal, e como deve a crítica feminista avaliar os discursos científicos que alegam estabelecer tais 
"fatos" para nós? Teria o sexo uma história? Possuiria cada sexo uma história ou histórias diferentes? Haveria uma história de como se estabeleceu uma dualidade do sexo, uma genealogia capaz de expor as opções binárias como uma construção variável? Seriam os fatos ostensivamente naturais do sexo produzidos discursivamente por vários discursos científicos a serviço de outros interesses políticos e sociais? Se o caráter imutável do sexo é contestável, talvez o próprio construto chamado "sexo" seja tão culturalmente construído quanto o gênero; a rigor, talvez o sexo sempre tenha sido o gênero, de tal forma que a distinção entre sexo e gênero revela-se absolutamente nula. (BUTLER, 2015, p. 27)

\section{A GENEALOGIA DO GÊNERO OU O GÊNERO COMO CONSTRUÇÃO SOCIAL E CULTURAL DO SUJEITO DE DIREITO}

O problema de uma perspectiva repressora conforme criticada por Michel Foucault em História da Sexualidade I, é que sob tal perspectiva imagina-se, seja por teorias psicanalíticas baseadas no tabu do incesto ou no tabu da homossexualidade, ou pela ideia de um sujeito pré-discursivo pressuposto pelos discursos jurídicos para delinear um sujeito de direito, uma categorização do sexo e gêneros como predominantemente binários, ou masculino ou feminino, e anteriores a própria criação da normatividade hétero. A "Lei”, na concepção de Butler e Foucault, antecede o gênero e o cria de forma fictícia como sendo pré-discursivo e depois “acredita” em seu próprio mito.

Judith Butler analisa que "Foucault observa que os sistemas jurídicos de poder produzem os sujeitos que subsequentemente passam a representar" (BUTLER, 2015, p.18) e que "os sujeitos regulados" por estruturas políticas "são formados, definidos e reproduzidos de acordo com as exigências" dessas estruturas (p.19). De forma que aquilo mesmo que o poder mesmo produz ele mesmo alega representar:

Em outras palavras, a construção política do sujeito procede vinculada a certos objetivos de legitimação e exclusão, e essas operações políticas são efetivamente ocultas e naturalizadas por uma análise política que toma as estruturas jurídicas como seu fundamento. O poder jurídico "produz" inevitavelmente o que alega representar; consequentemente, a política tem de se preocupar com essa função dual do poder: jurídica e produtiva. Com efeito, a lei produz e depois oculta a noção de "sujeito" perante a lei, de modo a invocar essa formação discursiva como premissa básica natural que legitima, subsequentemente, a própria hegemonia reguladora da lei. (p.19-20)

A criação ficcional do sujeito de direito é de um sujeito determinado e produzido pela lei e que mascara sua própria criação ficcional na medida em que generaliza subjetividades e singularidades sob esta criação que diz representar. Ou seja, a lei só representa aquilo que ela mesmo criou. Butler denuncia a circularidade do raciocínio jurídico na criação do sujeito de direito. O sujeito que a lei define como tal é uma criação da própria lei, aquelas definições dadas pelo direito ao sujeito não são definições naturais e ontológicas do que é o sujeito, como quer aparentar o Direito. 
Certamente, a questão das mulheres como sujeito do feminismo suscita a possibilidade de não haver um sujeito que se situe "perante" a lei, à espera de representação na lei ou pela lei. Talvez o sujeito, bem como a evocação de um "antes" temporal, sejam construídos pela lei como fundamento fictício de sua própria reinvindicação de legitimidade. A hipótese prevalecente da integridade ontológica do sujeito perante a lei pode ser vista como o vestígio contemporâneo da hipótese do estado natural, essa fábula fundante que é constitutiva das estruturas jurídicas do liberalismo clássico. [...] premissa básica a garantir uma ontologia pré-social de pessoas que consentem livremente em ser governadas, constituindo assim a legitimidade do contrato social.(p.20)

Butler mostra que o poder político que cria a lei para legitimar-se a si mesmo enquanto poder soberano, baseia-se em um contrato social fictício, como o de Hobbes, por exemplo, para justificar a ideia de indivíduos que abriram mão de sua liberdade em prol de um Estado soberano. Assim, o direito como um todo, é baseado em ficções, mas mascara-as ao postular certas naturalidades aparentes como o gênero. Fazer a genealogia do gênero é mostrar que o sujeito "só se faz inteligível por meio de sua aparência de gênero" (BUTLER, 2015, p.70).

O que fica claro após a leitura de Problemas de Gênero é a perspectiva da produção cultural e social do gênero e do próprio sujeito, contra uma perspectiva de determinismo biológico no que se refere ao gênero. Não existe para Butler um agente que anteceda a própria ação. Não existe um sujeito antes do assujeitamento. O que existe é um sujeito que se faz na ação. Daí porque para Butler, gênero, além de efeito, é ação, gênero é fazer, conforme define Butler (2015, p.69) "O gênero é a estilização repetida do corpo, um conjunto de atos repetidos no interior de uma estrutura reguladora altamente rígida, a qual se cristaliza no tempo para produzir a aparência de uma substância, de uma classe natural de ser."

E neste sentido Butler não admite uma ontologia do gênero, pelo menos, não uma ontologia metafísica. Mas talvez, mutatis mutandis, uma ontologia mais existencialista como a de Sartre que dizia que "o homem nada é além do que ele se faz" e "um homem não é outra coisa senão uma série de empreendimentos, a soma, a organização, o conjunto de relações que constituem essas empreitadas" (SARTRE, 2010, p.25 e 43), embora a própria Butler não deve ser considerada como existencialista, dada ainda uma certa metafísica dessa corrente, inegável considerar a influência destes autores sobre o seu pensamento. $^{99}$

Sua crítica às próprias feministas e à psicanálise deve-se a postulação que estes autores ainda têm de uma subjetividade que anteceda a própria ação. A ação e o fazer são temas fundamentais em Butler ligadas ao conceito de performatividade e paródia, que ela desenvolve no último capítulo de Problemas de Gênero. Performatividade são os atos reiterados do sujeito a partir daquilo que os discursos definem como enquadramento de sua identidade. Quando o médico, analisando o sexo da criança, mais especificamente o órgão sexual, determina sua identidade de gênero como "menina" ou "menino", os pais, a sociedade e

\footnotetext{
${ }_{99}$ Os trabalhos de Butler estão cheios de referências aos existencialistas Simone de Beauvoir e Jean-Paul Sartre, como é o caso, por exemplo de sua tese de doutoramento Subjects of Desire, 1984 em que dedicou um capítulo a recepção do pensamento de Hegel por Sartre, ou mesmo em Problemas de Gênero onde a autora parte da famosa frase de Simone de Beauvoir "Ninguém nasce mulher, torna-se mulher".
} 
a própria criança passam a repetir e reiterar atos dentro de enquadramentos do que é entendido socialmente como próprio de "meninos" e "meninas". Ocorre que o que estava ali na visão do médico e no corpo da criança, eram apenas órgãos físicos com potencialidades de determinadas funções fisiológicas. Quem generificou os órgãos, isto é o sexo, foi o discurso médico-biológico. Mas as ações reiteradas em torno dos órgãos são apenas imposições sociais-normativas e que nem sempre são da mesma forma em todos os lugares, por todos os indivíduos. Em outras palavras, não é porque o médico definiu que um órgão sexual é masculino e feminino, que o indivíduo necessariamente irá reproduzir atos performativos de gênero que corresponderiam aos seus órgãos sexuais. Até porque não foi do sexo que se originou o gênero, mas o sexo é que foi generificado. Tampouco os enquadramentos de sujeitos femininos e masculinos são originados no sexo, mas tratam-se sempre de convenções sociais. Não é a natureza quem define quem vai usar saia ou calça, quem vai obedecer ou ser obedecido, etc.

É no conceito butleriano de paródia onde se traz o riso para tudo isso, pois ela mostra que certos maneirismos, jeitos de se vestir, gestos e voz, etc. não são tão naturais assim quanto se imagina. Assim a figura da drag queen mostra que certo tipo de feminilidade é uma criação ficcional. A paródia, entendida como falsificação do real, mostra que o próprio real é ficcional. A paródia revela a ação e desmascara a origem natural das identidades.

É aqui em toda esta discussão trazida pelo método genealógico, justamente onde Butler se coloca ao lado de autores como Foucault e Nietzsche contra uma metafísica da substância, isto é, no caso de Butler, contra concepções pré-discursivas a respeito do sujeito, do sexo e do gênero:

O que é a metafísica da substância, e como ela informa o pensamento a respeito sobre as categorias de sexo? Em primeiro lugar, as concepções humanistas do sujeito tendem a presumir uma pessoa substantiva, portadora de vários atributos essências e não essenciais. A posição feminista humanista compreenderia o gênero como um atributo da pessoa, caracterizada essencialmente como uma substância ou um "núcleo" de gênero preestabelecido, denominado pessoa, que denota uma capacidade universal de razão, moral, deliberação moral ou linguagem. Como ponto de partida de uma teoria social do gênero, entretanto, a concepção universal da pessoa é deslocada pelas posições históricas ou antropológicas que compreendem o gênero como uma relação entre sujeitos socialmente constituídos, em contextos especificáveis. Este ponto de vista relacional ou contextual sugere o que a pessoa "é" - e a rigor, o que o gênero "é" refere-se sempre às relações construídas em que ela é determinada. Como fenômeno contextual, o gênero não denota um ser substantivo, mas um ponto relativo de convergência entre conjuntos específicos de relações, cultural e historicamente convergentes. (BUTLER, 2015, p. 32-33)

\section{PROCUPAÇÕES HEGELIANAS EM BUTLER SOBRE O SUJEITO}

Entendemos ser de fundamental importância, tanto para a compreensão das preocupações teóricas que movem o pensamento global de Butler como para a compreensão do tema que temos nos proposto, sobre a constituição do sujeito, fazer uma análise de outros textos produzidos pela autora. Um

Revista Lumen, v. 5, nº 9, Jan./Jun. - 2020 - ISSN: 2447-8717 
destes textos aos quais devemos recorrer é Subjects of desire: Hegelian Reflections in Twentieth-Century France, 1987. Trata-se de sua tese de doutorado sob a orientação do fenomenólogo americano Maurice Natanson, originalmente com o título apenas de Subjects of desire. Butler defendeu sua tese em 1984, mesmo ano que faleceu o filósofo Michel Foucault, o autor que veio a ser de grande importância para o seu pensamento. A obra é um estudo das relações entre sujeito, desejo e reconhecimento na Fenomenologia do Espírito de Hegel e a recepção do pensamento hegeliano sobre estes temas na França no século XX.

A primeira edição ${ }^{100}$ constava com uma análise inicial do sujeito, do desejo e o reconhecimento na Fenomenologia de Hegel, seguida de um estudo sobre a recepção do pensamento de Hegel a respeito do desejo por Alexandre Kojéve, Jean Hiyppolite e Jean-Paul Sartre. Em uma edição revisada pelos anos de 1985-1986, anos em que ela deu o seminário “Gender, Identity, and Desire” na Wesleyan University e em Yale (BUTLER, 2015, p.14) no qual já estava gestando seu Gender Trouble lançado em 1990 e que se tornaria sua obra mais conhecida, mais tarde, em uma nova edição, Butler acrescentou mais um capítulo sobre esta recepção francesa do pensamento hegeliano a partir dos desenvolvimentos filosóficos de Derrida, Foucault, Lacan e Deleuze.

Embora Judith Butler mencione que este texto é uma obra de juventude (BUTLER, 2012, p.10), da qual pede um certo cuidado e benevolência da parte do leitor, não pode ser considerado desconectado de suas preocupações e de outros de seus desenvolvimentos teóricos presentes em outros textos, principalmente no que se refere ao sujeito. Ela mesma se pronuncia informando que as preocupações de todo o seu trabalho filosófico seguem sendo hegelianas:

Em certo sentido, todo meu trabalho segue inscrito dentro da órbita de um conjunto de perguntas hegelianas: Qual é a relação entre desejo e reconhecimento, e a que se deve que a constituição do sujeito suponha uma relação radical e constitutiva com a alteridade?101 (BUTLER, 2012, p.19)

$\mathrm{Na}$ introdução, Butler mostra que na história da filosofia houve uma certa relação de tensão entre o desejo e a filosofia, sendo o primeiro muitas vezes visto como um estorvo à própria filosofia e com desconfiança pelos filósofos, a ponto de que se extrai desse conflito a ideia de que o desejo deve ser controlado para que a razão prevaleça, posto que o desejo estabelece o caos e não a ordem, marca da filosofia. "Desejar o mundo e conhecer seu significado e sua estrutura apareciam como empresas em conflito."102 (BUTLER, 2012, p. 29). Butler, ao contrário, quer demonstrar que o desejo é uma mola propulsora ao conhecimento e a reflexão e busca entender de que forma entre o desejo e a filosofia pode

\footnotetext{
${ }^{100}$ Butler nesta primeira fase de sua carreira acadêmica estava voltada para os estudos fenomenológicos em cursos que assistiu sobre Marx, Hegel, Heidegger, Kierkegaard e Merleau-Ponty. Foi somente depois assistindo aulas sobre feminismo que teve seus primeiros contatos com a obra de Michel Foucault, assim Butler se inserirá cada vez mais no movimento pósestruturalista. (BUTLER, 2012, p. 9-10)

101 Traduzido livremente para o português da versão em espanhol.

102 Traduzido para português da versão em espanhol de Subjects of Desire: "Desear el mundo y conocer su significado y su structura aparecían como empresas en conflicto." BUTLER, Judith. Sujetos del deseo. Reflexiones hegelianas en la Francia del siglo XX. Traducción de Elena Luján Odriozola - 1ª ed. - Buenos Aires: Amorrortu, 2012.
} 
haver uma mútua cooperação que resulte em reflexão filosófica. Para ela, o desejo é um impulso vital que nos direciona ao próprio conhecimento, fazendo de nós "seres filosóficos" (p.31). Buscar uma integração entre o desejo e a filosofia, é buscar a integração do próprio sujeito. Neste sentido moral e desejo se encontram imbricados, pois para a conquista da moral sempre se reportou nas filosofias da moral uma repressão e subjugação do desejo, o que acaba por impossibilitar a uma moral efetivamente autônoma. Para superar isso seria necessário incluir o desejo em todo o projeto metafísico ou ontológico do sujeito. Butler diz que

Segundo Spinoza e Hegel, o lugar metafísico do sujeito humano se define por meio da racionalidade imanente do desejo, posto que o desejo é, ao mesmo tempo, a luta fundamental do sujeito humano e o modo mediante o qual esse sujeito redescobre e constitui seu necessário lugar metafísico. (BUTLER, 2012, p. 34)

Assim, analisando a Fenomenologia do Espirito de Hegel, numa apropriação muito peculiar, Butler

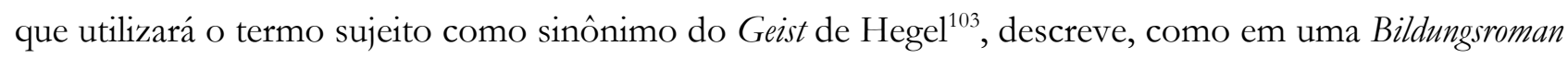
(novela alemã) em que o herói parte do desconhecimento para uma aventura rumo ao conhecimento de si, o sujeito movido pelo desejo de reconhecimento conhecerá o mundo e a si mesmo num movimento chamado de dialético (SALIH, 2015, p. 34-35). O sujeito em contato com os objetos do mundo e a medida em que elas aparecem ao sujeito, decifra-as por meio do pensamento e da linguagem, ao fazer isto, nega-se as próprias coisas, posto que o que está no pensamento já não é mais a coisa em si, mas apenas o pensamento sobre a coisa, como que devorada pelo sujeito movido por seu desejo. Se o pensamento já não é a coisa ou o objeto, o pensamento é o sujeito refletindo o objeto e ao refletir o objeto o sujeito vê a si mesmo, e portanto torna-se assim consciência-de-si, ou sujeito reflexivo, o que mostra que, para que o sujeito afirme-se a si mesmo, necessariamente tem que negar o objeto. Assim, a consciência-de-si é negatividade. Mas ao mesmo tempo neste processo vemos o aspecto da materialidade imbricada na constituição do sujeito, numa relação em que linguagem e materialidade estão integradas nesta constituição.

Conclui-se assim, que o sujeito só se reconhece a partir de outro: um objeto ou outro sujeito. Portanto, para se reconhecerem mutuamente, ambos o sujeito e o Outro, desejam um ao outro, e negam um ao outro em uma relação de poder e dominação. É na chamada dialética do senhor e do escravo que tal fato ilumina-se. O sujeito é assim movido pelo desejo de Outro, pelo desejo de reconhecimento. Este é o processo identitário, em que o sujeito busca em outro o conhecimento de si para se afirmar como sujeito que é, mas que só é na medida em que nega o outro. O Outro lhe serve na medida em que lhe aparece enquanto outro que também é sujeito, mas ao refletir este outro, o sujeito nega-o enquanto tal, para poder afirmar-se enquanto tal, enquanto consciência de si. Portanto o sujeito para reconhecer-se

\footnotetext{
${ }^{103}$ Esta questão tem sido objeto de crítica da parte de alguns. Entretanto, Butler não é a primeira a fazer isso. Giovanni Gentili,
} em em 1920, usou e abusou do termo sujeito numa referência direta a Fenomenologia do Espírito de Hegel. (ABBAGNANO) 
enquanto tal passa necessariamente por uma relação de alteridade e de poder que o outro exerce sobre o sujeito.

Os efeitos dessa dominação na formação da consciência-de-si, tornada em consciência infeliz, baseada na Fenomenologia do Espírito de Hegel, que estruturam como o sujeito aí mesmo se constitui, serão melhor desenvolvidos no texto de Judith Butler de 1997, A vida psíquica do poder. Nessa relação de poder e dominação o sujeito é paradoxalmente subordinado às normas que ao mesmo tempo são subjetivadoras (BUTLER, 2017, p.51).

Se por um lado as preocupações de Butler permanecem com questões hegelianas, por outro lado,

81 já em Problemas de Gênero, publicado em 1990, parece ficar claro que Butler ampliará esta concepção da constituição do sujeito pela dialética hegeliana, para uma perspectiva mais foucautiana, na medida em que considera a abordagem de Foucault sobre o poder enquanto produtor do sujeito. ${ }^{104} \mathrm{E}$ isso fica cada vez mais evidente nos textos publicados nos anos seguintes.

\section{CONSIDERAÇÕES FINAIS:}

Ao tratar da relação entre sujeito e poder que produz o sujeito, o texto e o empenho de Judith Butler é um empreendimento político. Fundamentando em como o sujeito se constitui ou é constituído no mundo a partir do Outro, Butler denuncia os mecanismos de controle e de poder que são responsáveis nesta constituição e ao mesmo tempo, por enquadrarem quem são os sujeitos de direito que merecem viver, que são dignos de luto ${ }^{105}$, e que portanto possuem reconhecimento. Ler Judith Butler demanda movimentar uma série de conceitos e abordagens filosóficas, psicanalíticas e antropológicas e fazê-las balançar todas em torno de seus próprios pressupostos. Estes, que por cristalizarem identidades, são negados e mascarados do fato de que são construtos sociais criados a partir da conveniência de certa organização e administração dos corpos. Neste sentido, as ciências humanas, o Direito e de maneira geral as áreas do conhecimento, estão comprometidos com esta visão essencializada e substantivada que determina quem é sujeito e quem não é, quais são os aceitáveis e quais não são. Surge assim a figura do “Abjeto" para utilizar um termo de Julia Kristeva, autora comentada por Butler, daquele que é negado ou não reconhecido enquanto sujeito de direito e que portanto deve ser expelido da sociedade: “O ‘abjeto'

104 É o que parece sugerir quando ela diz no prefácio de Gender Trouble "Contudo, essa reviravolta dialética do poder não pôde reter minha atenção - embora outras o tenham feito seguramente. O poder parecia ser mais que uma permuta entre sujeitos ou uma relação de inversão constante entre um sujeito e um Outro; na verdade, o poder parecia operar na própria produção dessa estrutura binária em que se pensa o conceito de gênero.” (BUTLER, 2015, p.8). Além disso, toda a perspectiva de Gender Trouble faz o percurso de uma genealogia do gênero a partir de uma abordagem foucaultiana do poder não enquanto hierarquia, mas sim enquanto produtor de sujeitos e se se assujeitam a esse poder.

105 Em Quadros de guerra: Quando a vida é passivel de luto?, publicado em 2009, Butler escreveu uma antologia de artigos sobre a questão do enquadramento a que os sujeitos estão sujeitos para serem considerados dignos de viver, a partir da observação sobre a política neoimperialista perpetrada pelo governo George W. Bush. (BUTLER, Judith. Quadros de guerra: Quando a vida épassivel de luto. Tradução de Sérgio Lamarão e Arnaldo Marques da Cunha. 2 ed. Rio de Janeiro: Civilização Brasileira, 2016.) Tal conceituação remete a biopolitica desenvolvida por Foucault na qual a administração governamental da população tinha $\mathrm{O}$ objetivo de "fazer morrer, deixar viver" e "fazer viver, deixar morrer". (FOUCAULT, Michel. Em defesa da sociedade. Tradução de Maria Ermantina Galvão. São Paulo, Martins Fontes, 1999.) 
designa aquilo que foi expelido do corpo, descartado como excremento, tornado literalmente 'Outro"' (BUTLER, 2015, p.230).

Desta forma, a leitura dos textos de Judith Butler não apenas demanda esforço intelectual, articulação com os muitos autores aos quais faz referência, como também demanda coragem posto que desafia crenças estabelecidas e enraizadas nas próprias identidades dos sujeitos. Neste sentido a leitura de Butler pode ser causa de muitos problemas. Mas como diz a própria autora no prefácio de se Problemas de Gênero "problemas são inevitáveis e nossa incumbência é descobrir a melhor maneira de criá-los, a melhor maneira de tê-los” (BUTLER, 2015, p. 7). Seria Butler um risco? Um perigo? Mas para quem? Talvez ela mesma não. Mas a sua teoria certamente incomoda aqueles que desejam que os poderes se conservem como estão. Trata-se antes de uma crítica aos que desejam continuar negando direitos às mulheres, LGBT's, negros, refugiados, palestinos, etc. Crítica aos que desejam continuar mascarando os seus pressupostos frágeis construídos sobre o sujeito de direito, como se fosse uma identidade definitiva e predeterminada.

Não é nenhuma coincidência o fato de Butler ser responsável pela cátedra de Hannah Arendt na Universidade da Califórnia, Berkeley, em que leciona, filósofa com a qual guarda muitas semelhanças: judia, mulher, filósofa política e residente nos Estados Unidos e que deu grande importância para a questão da ação política (Lembremos do texto de Arendt $A$ Condição Humana). E os textos de Judith Butler, além de filosóficos, são eminentemente políticos, posto que mostram a importância da ação como constitutiva de sujeitos. A conclusão de Problemas de Gênero dedica-se precisamente ao tema da ação. Mais do que um livro sobre liberdade de mudanças de gênero, é um texto de política que pretende não a mera libertação para meramente se performar gêneros, mas que pretende mostrar que é pela ação que sujeitos se constituem, ainda que dentro de "cenas interpelativas", para utilizarmos uma linguagem althusseriana apropriada pela filósofa americana.

Daí a importância e a continuidade que Butler faz do trabalho de Foucault no que se refere a estética da existência, onde Foucault coloca que é ali mesmo onde o sujeito é sujeitado, é que se forma e se constitui e pode fazer a crítica de si mesmo, ainda que dentro desta mesma relação de poder que se exerce sobre ele, é aí mesmo que o sujeito cria sua estética de existência. Já o disse, Foucault, “onde há poder, há resistência”. Para Butler, semelhantemente. Não se trata de uma promessa libertária. O poder captura as resistências. Foucault bem o sabia e Butler também. Mas ainda que sujeitos sujeitados, é preciso ampliar os sentidos de "sujeito de direito", desenraizá-lo ao máximo e continuamente das fixações das leis, especialmente quando elas possuem um caráter que exclui certos sujeitos de seus enquadramentos. É isto o que está em jogo neste momento político em que alguns sujeitos advogam ter mais direitos do que outros sujeitos porque estão enquadrados em identidades aceitáveis e coerentes com seus corpos, porque tais corpos seriam determinantes para as identidades que assumiram. Os que não se enquadram não seriam sujeitos, mas abjetos, prontos para serem expelidos da sociedade dos "verdadeiros" sujeitos de direito. Talvez o que falte aos perseguidores de Butler não seja inteligência para ler seus textos, mas 
simplesmente desinteresse, por causa da consequência que traz ao ter que rever privilégios, dos quais certamente não querem abrir mão. O trabalho de Butler não é eliminar as crenças religiosas judaicocristãs, nem tampouco negar a biologia dos sexos. O que está em jogo para Butler é que as noções e conceitos que temos sobre esses “entes" ficcionais são precários e temporais, politicamente comprometidos.

\section{Referências}

83 BUTLER, Judith. A vida psíquica do poder: Teorias da sujeição. Tradução Rogério Bettonni. Belo Horizonte: Autêntica Editora, 2017 . Problemas de Gênero: Feminismo e subversão da identidade. Tradução de Renato Aguiar. 8 ed.

Rio de Janeiro: Civilização Brasileira, 2015. . Sujetos del deseo. Reflexiones hegelianas en la Francia del siglo XX. Traducción de Elena Luján Odriozola - $1^{\text {a }}$ ed. - Buenos Aires: Amorrortu, 2012.

CASTRO, Edgardo. Vocabulário de Foucault. Tradução Ingred Müller Xavier; revisão técnica Alfredo Veiga-Neto e Valter Omar Kohan. 2 ed. Belo Horizonte: Autêntica Editora, 2016.

FOUCAULT, Michel. A verdade e as formas jurídicas. Tradução Eduardo Jardim e Roberto Machado. 4 ed. Rio de Janeiro: Nau, 2013.

- História da Sexualidade 2: O uso dos prazeres. Tradução de Maria Thereza da Costa Albuquerque. São Paulo: Paz e Terra, 2014.

LOPES, Guacira Lopes (org.). Pedagogias da sexualidade. 2 ed. Belo Horizonte: Autêntica, 2000.

LUDWIG, Ralf. Fenomenologia do Espirito: Uma chave de leitura. Tradução de Enio Paulo Giachini. Petrópolis, RJ: Vozes, 2017.

SALIH, Sara. Judith Butler e a Teoria Queer. Tradução e notas de Guacira Lopes Louro. Belo Horizonte: Autêntica Editora, 2015.

SARTRE, Jean-Paul. O Existencialismo é um humanismo. Tradução de João Batista. Petrópolis, RJ: Vozes, 2010.

SINNERBRINK, Robert. Hegelianismo. Tradução de Fábio Creder. Petrópolis, RJ: Vozes, 2017.

TORRANO, Luísa Helena. O Campo da ambivalência: Poder, sujeito, linguagem e o legado de Michel Foucault na filosofia de Judith Butler. 2010. 134f. Dissertação (Mestrado em Filosofia) - Faculdade de Filosofia, Letras e Ciências Humanas, Universidade de São Paulo, São Paulo, 2010.

PRINS, Baukje e MEIJER, Irene Costeira. Como os corpos se tornam matéria: entrevista com Judith Butler. Tradução de Susana Bornéo Funck. Revista Estudos Feministas, Florianópolis, v. 10, n. 1, p. 155-167, 2002. Acessado pelo link: http://www.scielo.br/pdf/ref/v10n1/11634.pdf em 11/03/2018. 